\title{
High-dose methotrexate-induced acral erythema in two pediatric patients with acute lymphoblastic leukemia: a 17 pediatric case series of methotrexate induced acral erythema
}

Kazuhiro Noguchi ${ }^{1}$, Ryosei Nishimura ${ }^{1}$, Yasuhiro Ikawa ${ }^{1}$, Shintaro Mase ${ }^{2}$, Toshihiro Fujiki $^{2}$, Rie Kuroda ${ }^{2}$, Raita Araki ${ }^{3}$, Hideaki Maeba ${ }^{3}$, Akihiro Yachie ${ }^{3}$, and Taizo Wada ${ }^{3}$

${ }^{1}$ Kanazawa University Hospital

${ }^{2}$ Kanazawa Univ.

${ }^{3}$ Kanazawa University

November 25, 2020

High-dose methotrexate-induced acral erythema in two pediatric patients with acute lymphoblastic leukemia: a 17 pediatric case series of methotrexate induced acral erythema

Kazuhiro Noguchi, ${ }^{1}$ Ryosei Nishimura, ${ }^{1 *}$ Yasuhiro Ikawa, ${ }^{1}$ Shintaro Mase,${ }^{1}$ Toshihiro Fujiki, ${ }^{1}$ Rie Kuroda,${ }^{1}$ Raita Araki, ${ }^{1}$ Hideaki Maeba, ${ }^{1}$ Akihiro Yachie $^{1}$ and Taizo Wada ${ }^{1}$

1 Department of Pediatrics, School of Medicine, Institute of Medical, Pharmaceutical and Health Sciences, Kanazawa University, Japan

* Correspondence to:

Ryosei Nishimura, MD, PhD. Department of Pediatrics, School of Medicine, Institute of Medical, Pharmaceutical and Health Sciences, Kanazawa University

13-1 Takara-machi, Kanazawa, Ishikawa 920-8641, Japan

Tel: +81-76-265-2314; Fax: +81-76-262-1866; E-mail: ryosein@me.com

Text word count: 500 words

A short running title: Methotrexate-induced acral erythema in pediatric cases

Keywords: Acral erythema, hand-foot syndrome, palmar-plantar erythrodysesthesia, methotrexate, chemotherapy side effects (3-6 words)

Table: 1

Supplemental figure: 1

TEXT:

Chemotherapy-induced acral skin reaction with sensory disorder has become widely known as acral erythema or hand-foot skin reaction. The incidence of acral skin reactions has increased with usage of kinase inhibitors in addition to conventional chemotherapeutic agents, especially in adult patients. In contrast, only a few dozen pediatric cases of acral skin reaction have been reported, although pediatric patients have increased the chance to receive kinase inhibitor treatment. Here, we report high-dose methotrexate-induced acral erythema in two pediatric patients with acute lymphoblastic leukemia (ALL). 
Case 1 was a 6 -year-old boy treated with oral 6-mercaptopurine once a day for 8 weeks and 24-h infusion of high-dose methotrexate $\left(2 \mathrm{~g} / \mathrm{m}^{2}\right)$ once every 2 weeks for four infusions. Three days after the first methotrexate infusion, painful erythema and bullae appeared in his left heel (Supplemental Figure 1) and he had disabled walking with spontaneous recovery. Although we prevented acral erythema with topical corticosteroid during and after the second methotrexate infusion, more serious lesions emerged after the third and fourth infusions. Therefore, systemic corticosteroid was needed to completely recover these lesions.

Case 2 was a 12-year-old boy treated with the same chemotherapy regimen as case 1 except for the methotrexate dose being $5 \mathrm{~g} / \mathrm{m}^{2}$. Erythema only with slight pain appeared in his bilateral heels (Supplemental Figure 1) after every methotrexate infusion. However, the lesions did not disturb his activity and systemic corticosteroid therapy was not required. Methotrexate clearance was not delayed in both cases.

The etiology of acral erythema remains unclear. Histopathologic features are nonspecific with findings of vacuolar degeneration of the basal layer, necrosis of keratinocytes, loss of epithelial polarity, and perivascular infiltration. Though acral erythema in much less common in children than in adults, methotrexate has been reported as the prominent causative agent of acral erythema in children. We summarized all 17 reported cases of methotrexate-induced acral erythema thus far, ${ }^{2-13}$ including our two cases (Table).

Overall, pediatric methotrexate-induced acral erythema developed 1-3 days after administration and resolved within 1-3 weeks. Almost all cases received high-dose methotrexate. Some physicians speculate that methotrexate clearance delay and renal impairment caused by high-dose methotrexate might be risk factors for acral erythema; however, in reports with data description, ${ }^{2-6,9,10,13} 9$ of 12 pediatric patients did not show delayed methotrexate clearance and 8 of 9 pediatric patients did not show renal impairment. Interestingly, ALL cases with methotrexate-induced acral erythema were older than the susceptible age for ALL, most often in children aged 2-3 years. We speculate that older children may have a higher risk of methotrexate-induced acral erythema.

Although some cases spontaneously recovered, several therapies including moisturizer, ${ }^{1,7,9}$ topical corticosteroid therapy, ${ }^{10}$ systemic corticosteroid therapy, ${ }^{4,13}$ and intravenous immunoglobulin ${ }^{7}$ have been reported. Among them, systemic corticosteroid therapy seems to be the most useful treatment, similar to adult cases when the erythema developed. ${ }^{14}$ Almost all cases were able to continue to receive high-dose methotrexate therapy repeatedly, even though the dose of methotrexate was reduced in some cases due to acral erythemarelated severe pain, probably contributing to maintain excellent cancer prognosis.

(500/500 words)

\section{Conflict of Interest Statement}

We have no conflicts of interest to declare.

\section{Acknowledgements}

K.N. wrote the manuscript. Y.I., S.M., T.F., R.K., R.A., A.Y. and R.N. provided patient care. T.W. was the principal investigator and takes primary responsibility for the paper.

\section{References}

1. Demirçay Z, Gürbüz O, Alpdoğan TB, Yücelten D, Alpdoğan O, Kurtkaya O, Bayik M. Chemotherapyinduced acral erythema in leukemic patients: a report of 15 cases. Int J Dermatol 1997;36(8):593-598.

2. Zils K, Wilhelm M, Reeh T, Bielack S. Bullous variant of acral erythema in a child after high-dose methotrexate. Pediatr Hematol Oncol 2012;29(4):378-379.

3. Postovsky S, Ben Arush MW. Acral erythema caused by high-dose methotrexate therapy in patients with osteogenic sarcoma. Pediatr Hematol Oncol 2005;22(2),167-173.

4. Werchniak AE, Chaffee S, Dinulos JG. Methotrexate-induced bullous acral erythema in a child. J Am Acad Dermatol 2005;52(5 Suppl 1):S93-95.

5. Hellier I, Bessis D, Sotto A, Margueritte G, Guilhou JJ. High-dose methotrexate-induced bullous variant of acral erythema. Arch Dermatol 1996;132(5):590-591. 
6. Millot F, Auriol F, Brecheteau P, Guilhot F. Acral erythema in children receiving high-dose methotrexate. Pediatr Dermatol 1999;16(5):398-400.

7. Tezer H, Kuskonmaz B, Kara A, Devrim I, Tuncer M, Cengiz AB, Yetgin S, Seçmeer G. Intravenous immunoglobulin in the treatment of severe methotrexate-induced acral erythema. J Pediatr Hematol Oncol 2008;30(5):391-393.

8. Aytaç S, Gümrük F, Cetin M, Tuncer M, Yetgin S. Acral erythema with bullous formation: a side effect of chemotherapy in a child with acute lymphoblastic leukemia. Turk J Pediatr 2010;52(2):211-214.

9. Varela CR, McNamara J, Antaya RJ. Acral Erythema with Oral Methotrexate in a Child. Pediatric Dermatology 2007;24(5):541-546.

10. Morrell DS, Challgren E, Eapen M, Esterly NB. Bullous acral erythema secondary to high-dose methotrexate. J Pediatr Hematol Oncol 2002;24(3):240.

11. Feizy V, Namazi MR, Barikbin B, Ehsani A. Methotrexate-induced acral erythema with bullous reaction. Dermatol Online J 2003;9(1):14.

12. Soker M, Akdeniz S, Devecioglu C, Haspolat K. Chemotherapy-induced bullous acral erythema in a subject with B-cell lymphoma. J Eur Acad Dermatol Venereol 2001;15(5):490-491.

13. Haga Y, Mitsui K, Matsuoka M, Kojima Y, Takahashi H, Ohara A. Methotrexate-induced bullous acral erythema in a 2-year-old girl with acute lymphoblastic leukemia. The Japanese Journal of Pediatric Hematology/Oncology 2016;53(3):309-313.

14. Brown J, Burck K, Black D, Collins C. Treatment of cytarabine acral erythema with corticosteroids. J Am Acad Dermatol 1991;24:1023-1025.

\section{Hosted file}

MTX induced acral erythema TABLE.pdf available at https://authorea.com/users/378574/articles/ 495039-high-dose-methotrexate-induced-acral-erythema-in-two-pediatric-patients-withacute-lymphoblastic-leukemia-a-17-pediatric-case-series-of-methotrexate-induced-acralerythema 